\title{
Getting Clear About Equivocal Concepts
}

Critical Notice of On Clear and Confused Ideas: An Essay about Substance Concepts, by Ruth Garrett Millikan

Nicholas Shea

King's College London

Disputatio No. 8

November 2002

DOI: $10.2478 /$ disp-2002-0010

ISSN : 0873-626X 
Disputatio 13, November 2002

\title{
CRITICAL NOTICE
}

\section{GETTING CLEAR ABOUT EQUIVOCAL CONCEPTS}

\author{
Nicholas Shea \\ King's College London
}

On Clear and Confused Ideas: An Essay about Substance Concepts, by Ruth Garrett Millikan, Cambridge: Cambridge University Press, 2000.

\section{INTRODUCTION}

Just how far can externalism go? In this exciting new book Ruth Millikan explores a radically externalist treatment of empirical concepts. For the last thirty years philosophy of mind's ties to meaning internalism have been loosened. The theory of content has swung uncomfortably on its moorings in a fickle current, straining against opposing ties to mind and world. In this book Millikan casts conceptual content adrift from the thinker: what determines the content of a concept is not cognitively accessible. She has only the stanchion of the world to hold her theory fast. She hopes that the tide will turn, and the theory of meaning will come stably to rest downstream of this anchor. This book is a bold exploration of how that might be achieved.

The book covers too much ground to be summarised in a review article. So I intend to take up only two of her topics, in order to make short observations on each. They are:

(1) What it is for a thinker to know what he is thinking of.

(2) How it can be that misidentifying produces equivocal concepts.

\section{OVERVIEW}

The first half of the book is a theory of one type of empirical concept, those of substances, in roughly the Aristotelian sense. For Millikan, concepts of these substances are abilities - the ability to identify the substance of which 
it is a concept. Associated 'conceptions' are the ways we actually pick out substances; but they play no role in determining the extension of a concept. Millikan denies any form of meaning rationalism: the thinker does not in general (except in very exceptional cases) have cognitive grasp of that which determines the reference of her concepts.

The second half of the book argues for various theses about empirical concepts in general, which together constitute a radically externalist theory of concepts. A prominent theme is her attack on neo-Fregean senses or modes of presentation. Another is her argument that, for the brain, there is no difference in principle between treating two concepts as identical and retyping the symbols for those concepts as being symbols of the same. Section III below explains how the use of 'concept' to refer to symbol types is compatible with thinking of concepts as abilities. The short answer is that Millikan employs a very liberal notion of 'representation' which allows that every ability to identify a substance will be mediated by an internal representation. That representation can be considered as a symbol for the referent of the concept. So 'concept' can be used to refer to the representation type, as well as the ability which it supports. Each use of 'concept' picks out a different ontological type. On the one hand it refers to an ability. On the other to a mental representation, which is part of the mechanism which realises that ability. However, for most purposes no confusion should arise in moving between uses, since they employ the same grain of analysis in the individuation.

\section{TWO ISSUES}

\section{(1) WHAT IT IS FOR A THINKER TO KNOW WHAT HE IS} THINKING OF

A traditional way of thinking about concepts holds that the conceptions we associate with a concept determine the reference of that concept. For example, for Frege sense determines reference. This gives a straightforward sense in which a thinker knows what he is thinking of: he grasps the sense and that determines the reference. But Millikan denies that conceptions play any role in fixing the reference of a concept. So she feels that she owes some account of how in her externalist theory a thinker nevertheless knows what he is thinking of. She provides a detailed theory of this phenomenon, which I survey in this section. The theory is pitched at three levels. The first is to argue that the requirement of 'knowing what you're thinking of' is very easily satisfied. On the only plausible understanding of that capacity, almost 
Nicholas Shea

any user of concepts will satisfy it. The second part of the theory is to explain how, empirically, thinkers can come to develop that capacity. ${ }^{1}$ The third stage is to see how as theorists of concepts we can reflect on our abilities so as to be reassured that our concepts are largely univocal, and not permeated with redundancy, equivocation and the confusion of the title of the book.

\section{(I) KNOWING WHAT YOU'RE THINKING OF}

Millikan denies that concept users do have or must have justification when applying a concept. Rather, they just exercise abilities to identify. Nonhuman animals can thus have concepts in exactly the same way as us. Millikan's account of 'knowing what you're thinking of' applies to all users of concepts, animal and human. In what, then, does this capacity consist?

Of course, we cannot hold a concept up against its referent (the substance itself) and compare them in thought, since substances only enter into thought through concepts. Nor is Millikan happy with the idea that we can satisfy this requirement by first using then mentioning the concept - the parallel in language would be " "horse" means horse'. In fact, it is not clear what she takes the requirement to be. It stems from something like the worries about externalism and self-knowledge which Gareth Evans addressed in The Varieties of Reference (1976). In any case, she feels she owes some kind of explanation in this area, and it is as follows. A thinker knows what he is thinking of when he uses a concept as a middle term in an amplificatory inference. For example when reasoning: yesterday's strawberries were tasty, here are some strawberries, so they are tasty. So to know what you are thinking of is not to possess propositional knowledge (of course), but rather to have the ability to put together two thoughts of a substance as being about the same, and then conclude something new.

How is that different from simply possessing the concept? After all, possessing a concept is having an ability to identify, whose function is to project properties over encounters. So the thinker must be able to reidentify the substance for the concept to fulfil its purpose. Does possessing a concept thus entail knowing what you're thinking of? The answer seems to be 'nearly, but not quite', since there may be ways of reidentifying a substance which fall short of using it as a middle term in mediate inference. Simultaneously identifying a substance through two sensory modalities requires

\footnotetext{
${ }^{1}$ In the book these parts of the theory are presented in the opposite order. Chapter 13 explains in what the capacity to know what you are thinking of consists, and chapter 7 sets out how thinkers can develop such capacities.
} 


\section{Getting Clear About Equivocal Concepts}

reidentification of the substance (ie, co-identifying the outputs of the two perceptual systems), but arguably without any form of mediate inference. However, the difference is minimal. For example, Millikan argues that even such subpersonal activity as using binocular images to perceive depth requires a co-identification of the content of the two images (and hence knowing what you're thinking of).

In short, the theory appears to be as follows. Concepts are abilities to identify, and thus reidentify. A special case of reidentification is pairing two uses of a concept as a middle term in mediate inference. In that case the thinker 'knows what he is thinking of'. It is not clear just how minimal this requirement is. Is it a mediate inference to identify a substance and then apply a known property to that substance, e.g., here is a cat, cats like fish, therefore he likes fish? If so, then any system which identifies substances by means of mental representations will, on occasion, satisfy the requirement of 'knowing what it is thinking of'. So perhaps the dialectic is as follows. Millikan feels that she must answer doubts that externalists can account for thinkers 'knowing what they're thinking of'. She then argues that the only sense which can be made of this requirement is that it requires the capacity to pair two concepts of a substance as a middle term in mediate inference. It seems to be a consequence of this theory that any cognitive system that identifies substances by means of mental representations will satisfy the requirement of knowing what it is thinking of. So be it - so much for the anti-externalist requirement.

Notice that Millikan's explanation of knowing what you are thinking of slips from thinking of concepts as abilities, however instantiated, to thinking of them as mental representations: symbols which are used in inferences. ${ }^{2}$ This is not, however, an objection to the account. When an ability to identify is mediated by an internal representation it is legitimate to consider that representation as a symbol for the concept. That is, the conceptual vehicle can be considered as a mental symbol type, where mental symbols are typed by their content. And content derives from the purpose of the ability which the symbol helps to realise. Say that on a particular occasion I identify a dog, and suppose that involves forming a mental representation. Then that token representation belongs to the symbol type DOG, deriving from the purpose of the ability. In a domain in which abilities to identify are supported by mental representations we can think of concepts either as abilities typed by purposes or as mental representations typed the same way. Put another way, where an ability to identify has a vehicle, a concept can be thought of as the vehicle typed by content.

\footnotetext{
${ }^{2}$ This move was discussed at the end of section II above.
} 
Nicholas Shea

\section{(II) DEVELOPING THE CAPACITY TO KNOW WHAT YOU'RE THINKING OF}

Now that the capacity to know what you're thinking of has been characterised, it can be asked how thinkers ever come to have that capacity. How do they come to be able to reidentify a substance and pair two tokens of a concept of it as a middle term in mediate inference? In chapter 7 Millikan gives an account of how concepts are so 'tuned'. That is by having diverse means of identifying a given substance in a variety of circumstances. Mistakes in identifying then show up in contradictions - properties which should apply to the substance will fail to apply to the misidentified instance. Adjusting to such contradictions allows animals to tune their concepts to a given substance, that is, to increase the range and variety of circumstances in which they can correctly identify it.

The idea is not that the thinker looks for contradictions or explicitly represents the law of non-contradiction. All that is required, rather, is a learning mechanism which is sensitive to the existence of contradictions and failed projections. The fact that misidentifications will throw up such contradictions in practice provides the basis on which conceptual development can be sensitive to such misidentifications. Similarly, a thinker starting out with a confused or redundant concept is not stuck with it. The conceptual confusion may show up in practice, and so can be corrected. This gives the thinker the material to become better at reidentifying substances. According to the characterisation in the last section, that is equivalent to becoming better at knowing what you're thinking of.

\section{(III) HOW WE CAN KNOW THAT OUR IDEAS ARE NOT CONFUSED}

Finally, it is worth noting that Millikan thinks there is another level of sophistication above knowing what you're thinking of, which is the level of judgement, of true thought or cognition, which probably only humans have attained. Millikan characterises this with something like Evans' (1976) generality constraint. Humans are distinctive in that many of their mental representations are designed to take part in a wide range of mediate inferences. We gather information for its own sake, and then later use it for unenvisaged purposes. Thus, she argues, many human concepts must be embodied in such a form that they are available to take part in inferences with any other concept. There is not scope in this review to consider whether Millikan is right about this characterisation of what is distinctive about human cognition. 


\section{Getting Clear About Equivocal Concepts}

So far I have outlined Millikan's account of in what the capacity to know what you are thinking of consists, and her ideas about how thinkers come to improve those capacities. That is all at the level of unreflective mechanism. But her theory gives us the materials to say something about how the theorist can have warrant for thinking her concepts are not confused; which I will call an 'epistemology of conceptual abilities'.

The potential worry with the story so far is that having an ability does not ensure you will use it correctly. You ride a bike, but sometimes you fall off. You can identify cows, but sometimes you get it wrong. Millikan has purpose, hence reference, determined historically, in virtue of the actual selectional history of the concept. ${ }^{3}$ But that account only entails that you are able correctly to identify cows (say) in those actual historical circumstances. If those circumstances did not include picking out cows on dark nights, you may well misidentify cows on dark nights. There is no reason why your ability should extend much beyond the circumstances of your past successes with the concept. And those circumstances might be far from statistically normal. For example, although some northern hemisphere aquatic animals called paramecia can identify the direction of deadly oxygen-rich water (using internal magnetosomes that detect the earth's field), and swim away from it, they will systematically get it wrong if put in the Southern Ocean where the magnetic field is reversed. How can we tell that our concepts are not like that?

Millikan gives us some answers. As humans we can derive assurance from the fact that we have multiple ways of identifying each substance. Indeed, the utility of a substance concept depends proportionately on the number and variety of different ways we have of identifying its referent. Each time two different component abilities agree that the concept applies, we have an assurance that we are getting it right, that we are within the range of circumstances where the component abilities correctly identify the substance. Different means of identifying a substance could disagree on the same exemplar, in which case either or both must be outside its normal range of operation. That would warn us that something is wrong with our means of identifying. For example, if it looks like a cat but sounds like a $\mathrm{dog}$, one of our ways of identifying must be going wrong. On the other hand, if it looks, sounds, feels and smells like a dog, we have additional assurance that we have correctly identified the substance.

\footnotetext{
${ }^{3}$ Since most human concepts are learned, reference is determined by a combination of selectional and learning history: see the theory of derived and adapted proper function in Millikan (1984).
} 
Nicholas Shea

It is not just through different sensory modalities that we can triangulate to the same substance. We may look at the same thing from two different perspectives, or through two different sets of mediating circumstances. For example, the temperature of a liquid can be measured by both a thermocouple and a mercury thermometer. The fact that the two agree provides support that a single property, temperature, is being measured. This is not undermined by the fact that theories are used to produce the readings given by each measuring device. The theory is part of the measuring system. Confirmation consists in the fact that the outputs of the two systems consistently agree.

It should be clear by now that Millikan is not claiming that in using our concepts we usually have grounds for thinking that we are correctly identifying their referents. Rather, we just go ahead and do it. There is no guarantee against unsuspected errors. Millikan's approach is to show that there are ways in which it becomes apparent to us when we incorrectly identify. In particular, in such cases different means of identifying will often disagree. It is not that when we are getting it right, we have grounds for justifying our application of the concepts, rather that when we are getting it wrong we have ways of telling, and often do notice. Which makes it less likely that we will make the kind of stable errors in applying our concepts that a paramecium would make in the Southern Ocean. So Millikan is not giving us an epistemology of judgement: saying how we have justification for our beliefs. In general she is suspicious of that idea, and in her picture we often just apply our concepts without justification. However, she does give us as theorists of concepts some justification for our practices in using our conceptual abilities. Given that we have diverse means for identifying substances, we would often notice when we misidentify: different component abilities would disagree. Similarly, when a concept shows no variety in the observational circumstances in which it applies, we should beware that the concept may be empty. Reflecting on the fact that usually we have diverse means of identifying which agree on cases does then give us justification for the use of that conceptual ability. You could mark the distinction by calling it an epistemology of conceptual abilities, rather than an epistemology of judgement.

However, notice that this means of auditing our conceptual abilities does need some quite sophisticated machinery. We must be able to make judgements of the sort, if $p$ then $p$, where $p$ states something that is the case. For example, if the cat is fluffy [seen], then the cat is fluffy [felt]. So we have to be able to represent states of affairs in subject-predicate form. Furthermore, if we are to recognise contradictions we have to be able to tell when the contrary of a predicate applies: the object on my lap [felt] is a cat, but the 
object on my lap [seen] is not a cat (... error!). That requires having the operation of negation and the ability to identify the contraries of predicates. All of which are highly sophisticated conceptual capacities. So the abilities by which we as theorists are able reflectively to derive some warrant for our conceptual abilities are probably not shared by many other animals.

\section{(2) PRODUCING EQUIVOCAL CONCEPTS}

The last section explained Millikan's account of how it can be that we know what we are thinking of and how we check that a concept is not empty or systematically misapplied. Now I will consider another kind of failure equivocation - when a thinker cannot distinguish between two substances and so has a concept which applies to both. There is a type of conceptual audit in which this shows up - we should notice that contradictions are systematically correlated with particular perspectives or means of identifying. The question for this section is how such equivocal concepts could ever arise.

Recall that our means of identifying a substance (our conceptions) do not fix the referent of a concept. That is the centrepiece of Millikan's denial of meaning rationalism. Rather, content is fixed by actual history. So the fact that a thinker would systematically misidentify a substance in some counterfactual circumstance does not alter the referent of the concept. Even if I would always judge horses on dark nights to be cows, that does not broaden the content of my concept to COW OR HORSE ON A DARK NIGHT.

However, Millikan insists that equivocal concepts do arise. They are the 'confused ideas' of the title to the book. Thus:

'If not soon corrected, mistaking the identity of an object of thought produces equivocation in thought, hence the beginning, at least, of change in the object of thought.' (Millikan 2000, ch. 13)

So it seems that actual misidentifications, rather than counterfactual ones, can alter the referent of a concept. How can that be? Surely if content is fixed by history, then even actual misidentifications should not be considered to impact upon content determination. The answer is that actual misidentifications become part of the history of that concept. Thus sufficient misidentifications can alter the history of the concept and thus what it is a concept of. Indeed, over time a concept of one substance could become equivocal and then shift to become a univocal concept of a second substance, even within the history of an individual thinker. 
Nicholas Shea

Millikan is on difficult ground here. It seems as if she is slipping towards verificationism. Not what could be called counterfactual verificationism, where dispositions to categorise determine content, but a kind of actualist verificationism in which the content of a concept is held to be all and only those things to which it has been actually applied. Perhaps there is theoretical room for Millikan to avoid this trap. If her account in Millikan (1984) of how learning fixes content can be sustained, then she would have the materials to formulate a distinction between misidentifications which are part of the development of a new concept, and those which are mere errors. However, none of that fine detail is found in the present book, which leaves a considerable worry about whether the theory ends up shading into verificationism about conceptual content.

Millikan also explains a second mechanism by which concepts can become equivocal, which is consistent with a strict historicism about content determination. This is the idea that equivocation arises when two concepts, which are not concepts of the same substance, are equated (treated as identical). For example, someone might wrongly conclude that their next door neighbour in Chelsea, Madge was in fact the pop star Madonna. According to Millikan's theory, in deciding that Madonna = Madge the thinker makes a functional change, merging their MADGE and MADONNA concepts and treating all the beliefs that have about either as true of a single individual. Millikan argues that the thinker ends up with an equivocal concept which is ambiguous between Madge and Madonna.

How that can be is at first puzzling. Externalists sometimes argue that the contents of concepts can be kept distinct, even if thinkers muddle them up. Each thought retains the content derived from its peculiar history. For example, consider Harriet who was brought up in Canada and used 'public school' to refer to State schools. She then moves to Britain where, after a while, she also learns and uses the phrase 'public school', which in Britain refers to private schools. Unreflectively she takes the words to mean the same in both countries. The externalist about content has the resources to explain how the contents of her two concepts can be kept separate. When Harriet uses 'public school' in a way which refers back to her Canadian memories it means State school. When her use connects with British memories or activities it means private school. This particular example depends upon the role of public language in determining content, but Millikan wants to deny a parallel phenomenon can occur in the case of thoughts. If Harriet treats the two concepts as the same in thought then she confuses them and ends up with a single concept whose content is equivocal between private and State schools. How is that position consistent with Millikan's externalism? 


\section{Getting Clear About Equivocal Concepts}

The answer to this puzzle is, I think, straightforward if you can keep hold of the distinctions - so hold tight. Equivocation arises when two different concepts are mistakenly paired together as a middle term for mediate inference. In getting clear about this, it is important to recall the observation in the last section that, where mental representations are the vehicles of conceptual abilities, Millikan sometimes identifies concepts with types of those vehicles. At the start of an inference, two different identificatory abilities produce two different concepts (vehicles). Each concept has a different and unequivocal extension, deriving from the different purposes of the abilities which produced them. But then the two concepts are paired as a middle term in a mediate inference, producing a conclusion which also contains a concept (vehicle). What is the extension of that concept? As usual, the answer is given by looking at actual history. But we have a bifurcating history and hence two different purposes. So the vehicle token in the conclusion of the piece of reasoning has an ambiguous content: it applies to both substance A and substance B. It is equivocal. If a thinker systematically treats the outputs of two different conceptual abilities as identical, then those abilities effectively merge. The thinker no longer has two abilities, one to identify A and the other to identify B. Rather, she has a single ability to identify $\left\{\right.$ A or B . $^{4}$

To return to our example, Harriet ends up with an equivocal concept of PUBLIC SCHOOL. A radical externalist wants to say that one use may have an American history and thus mean State school, another a British history and thus mean private school. By their separate histories the symbols have different contents, although the thinker does not distinguish between them. Millikan points out that there is no possibility of tracing each token use of this concept back to a separate history once the concepts have been paired as a middle term in mediate inference. In effect, each token has a history running back to both American and British uses. So Millikan disagrees with those externalists who argue that the concepts remain distinct. Notice however that equivocal concepts only arise in this way when treated the same by a single thinker. Identical treatment by two different thinkers does not, on Millikan's theory, lead to equivocation; so Putnam's original idea is preserved, namely that Oscar and Toscar on different planets can have water thoughts with different contents even though they are intrinsic duplicates and so treat their water concepts in the same way.

So Millikan reaches the right result. She can deny that two of a thinker's concepts could have different contents if he treated them as identical for all purposes. Indeed, that follows from fixing the contents of concepts by their

\footnotetext{
${ }^{4}$ Which is different from having the disjunctive content A OR B, which would require the separate representation of the components.
} 
Nicholas Shea

purposes. Her externalism agrees with a common intuition which is otherwise would be used as a rebuttal by anti-externalists.

Millikan's treatment of equivocal concepts also fits nicely with her account of identity judgments. Recall that what it is to accept an identity claim like Mark Twain = Samuel Clements, in her view, is to treat mental tokens of the two concepts as indistinguishable in mental processing. That is just what is going on in pairing two concepts together as a middle term in mediate inference. Mental reasoning treats the two separate concept tokens as the same in order to reach its conclusion. So mistaken identity judgments produce equivocal concepts. For example, the practice of $17^{\text {th }}$ century scientists of identifying the intensive quantity temperature with the extensive quantity heat gave them a confused concept HEAT/TEMPERATURE. Notice that on Millikan's theory identity judgments are not propositional, rather they are the means of achieving a functional change in the reasoning architecture - they are effectively the merging of two concepts (if concepts are read as abilities, the two distinguishable abilities become one, if concepts are read as vehicles, the two distinct mental symbol types become typed as identical). There is not scope here to criticise Millikan's controversial theory of identity judgments, but just to observe that it is consistent with her theory of equivocal concepts.

A similar story can be told about redundant concepts. Two distinct conceptual vehicle types will actually co-refer if they are produced by mechanisms whose purpose is to identify the very same substance. If those vehicles are not treated as of the same type in later processing, then there is a problem with the thinker's conceptual set up. He has redundant concepts. He fails to make inferences which he could otherwise make. Millikan thinks there is a kind of conceptual auditing in which redundancy will show up, in the sense of the previous section: typically the two concepts will accumulate the same properties in their associated conceptions, without also having contradictory properties. However, to remedy redundancy takes a functional change: the thinker must mark the two vehicle types as identical, so that they may be taken as such when needed and used as a middle term in inference. Merging redundant concepts cannot on any view be described propositionally. Millikan describes it functionally. This has a nice parallel with her story of what happens in the cases of identity judgements which are described propositionally (Mark Twain $=$ Samuel Clements). These too are functional changes, mergings of files.

Millikan's ideas about redundant concepts are deeply anti-Fregean. Her view is that a thinker can rationally have two concepts with the same content which he fails to identify. Fregeans individuate content at the level of cognitive significance, making that move impossible. For a Fregean, if it is 


\section{Getting Clear About Equivocal Concepts}

rationally possible to think different thoughts involving two concepts, then they must have different contents (different senses). Millikan embraces the anti-Fregean consequence of her theory and explains at length why she thinks there are no such things as Fregean senses. That is a highly ambitious project, but I will not question it here. Instead I will look briefly at Millikan's discussion of the relations between the contents of concepts and their vehicles. This is the topic which Millikan refers to as externalising / internalising sames / sameness etc. (chapter 9). The basic idea is that, as a thinker can have redundant concepts he cannot assume that concepts with different vehicles have different contents. Equivalently, sameness of content does not imply sameness of vehicle.

Care is needed here about how the vehicles are typed. Recall that where an ability to identify a substance is mediated by a mental representation, we type together all such representations (ie, by their content). That vehicle type is a symbol for the substance. Equivalently, mental representations typed that way are concepts. This is a fully externalist typing. Representations are not typed in virtue of any of their intrinsic properties, but rather in virtue of what substances they are representations of. So Millikan rightly warns against assuming that any intrinsic properties of mental symbols carry over to their contents. Symbols which are intrinsically indiscernible may have different contents if they are used to identify different substances, and symbols which are intrinsically discernible may have the same content. The previous paragraph made the point that even symbols which are treated differently by the thinker may not have different content. That is a different level of typing again: it is typing symbols on the basis of how they are treated in processing. On this typing, symbols which have intrinsic differences to which the thinker is insensitive are still typed together: they are treated as the same. It is a kind of internal extrinsic typing. The representations are typed on the basis of a relational property - how they would be treated in processing - but one that is defined only internally to the thinker. In short, there are three ways of typing mental representations in play here:

(1) In terms of their contents.

$$
=\text { fully externalistically }
$$

(2) In terms of the intrinsic properties of the representation.

$$
=\text { fully intrinsically }
$$

(3) In terms of how they are treated in mental processing (all representations which are treated the same in processing form an equivalence class, which is a typing)

$$
=\text { internal-relationally }
$$


Nicholas Shea

In general Millikan is right to point out that sameness / difference at any of the levels (1) - (3) does not carry over to any of the other levels. However there is an important exception to this principle, which Millikan does not explicitly draw out in the book. It arises from her theory of identity and equivocation which I set out above. If two concepts (symbols) of different substances are treated as identical by the thinker and paired together in a mediate inference, then the resulting concept will be equivocal between the two substances. So the two concepts thereby acquire the same (ambiguous) content. That is to say, concepts which are treated by the thinker as concepts of the same become concepts of the same. Of course, given enough confusion the thinker will cease to have a concept at all. But in the usual case this type of confusion will produce a concept with an equivocal content. Thus, as an exception to Millikan's general arguments against internalising / externalising moves, there is a property of conceptual vehicles which carries over to their contents. When vehicles are typed by how they are treated in internal processing, if they are typed as the same then they will have the same content. In terms of the categories above, sameness of (3) implies sameness of (1). (But not the converse: concepts with the same content may nevertheless be treated differently, ie, redundancy.) Equivalently, difference of content (typing (1) above) implies that the thinker must treat the representations differently in processing (typing (3)).

That is not yet to say that the thinker can tell when two of his concepts have the same content. It is unlikely to be fully cognitively transparent whether or not two symbols are treated as the same by all processing. But it is at least something which the thinker might be able to tell and might be able to make warranted judgements about. So it is unlike the Fregean test of difference of content in two respects. First, it does not make thinkers' rational judgements constitutive of difference in content. Second, it goes in the opposite direction - same internal treatment implies same content. The Fregean criterion is that different internal treatment implies different content.

Two final observations will help to show how this theory fits into wider debates about externalism. First, as observed above, the Putnam-style thought experiments are preserved. Identical thinkers in different contexts can have thoughts with different contents although they threat their concepts the same. It is only when concepts are treated as identical within a thinker, and paired as a middle term in a mediate inference, that equivocation and hence sameness of content arises. A second externalist thought is also preserved: two concepts in the same thinker may have different contents in virtue of different histories, even if they are intrinsically identical. It is only if they are thereby paired as middle term in mediate inference that they 


\section{Getting Clear About Equivocal Concepts}

become equivocal. If they are kept separate, for example by arising in different cognitive systems, their separate contents are maintained.

Nicholas Shea

Dept. of Philosophy

King's College London

Strand, London WC2R 2LS

UK

\section{References}

Dretske, F. 1980. Knowledge and the Flow of Information. Cambridge, M.A.: MIT Press.

Evans, G. 1976. The Varieties of Reference. Oxford: Clarendon Press.

Millikan, R. 1984. Language, Thought and Other Biological Categories. Cambridge, MA: MIT Press.

Millikan, R. 2000. On Clear and Confused Ideas. Cambridge: Cambridge University Press. 